\title{
Enhanced Thermal Emittance of Space Radiators by Ion-Discharge Chamber Texturing
}

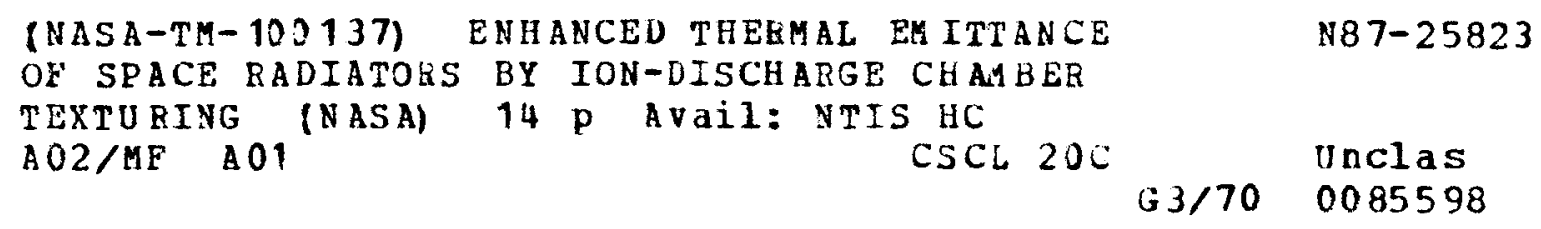

Michael J. Mirtich

Lewis Research Center

Cleveland, Ohio

and

Michael T. Kussmaul

Cleveland State University

Cleveland, Ohio

Prepared for the

International Conference on Metallurgical Coatings

sponsored by the American Vacuum Society

San Diego, California, March 23-27, 1987 
ENHANCED THERMAL EMITIANCE OF SPACE RADIATORS BY ION-DISCHARGE

CHAMBER TEXTURING

\author{
Michael J. Mirtich \\ National Aeronautics and Space Administration \\ Lewis Research Center \\ Cleveland, Ohio 44135 \\ and \\ Michael T. Kussmaul \\ Cleveland State University \\ Cleveland, Ohio 44175
}

\begin{abstract}
SUMMARY
The discharge chamber of a $30 \mathrm{~cm}$ argon ion source was successfully used to texture potential space radiator materials for the purpose of obtaining values of thermal emittance greater than 0.85 at 700 and $900 \mathrm{~K}$. Some samples were also treated in acid prior to texturing. To evaluate the durability of the textured materials to atomic oxygen, samples were exposed to an RF air plasma environment. The spectral emittance between 2.0 and $15.0 \mu \mathrm{m}$ was measured before and after the textured materials were exposed to the plasma asher. The results indicate that copper with extremely high values of emittance after texturing $(0.978$ and 0.983$)$ at 700 and $900 \mathrm{~K}$ respectively did not change its value of emittance after ashing, whereas the emittance of stainless steel fell below 0.85 after ashing. These data, along with scanning electron photomicrographs, and the results of texturing and ashing titanium and $\mathrm{Nb}(1) \mathrm{Zr}$ are presented in this paper.
\end{abstract}

\title{
INTRODUCTION
}

Power requirements for the Space Station and spaced based nuclear reactors require the development of improved radiators for waste heat rejection. To minimize the radiator size, surfaces are required to not only have high emittance at the radiator operating temperature, but also be durable to atomic oxygen and maintain high emittance in the low earth orbital environment. As an example, the SP-100 Power System, a $100 \mathrm{~kW}$ space nuclear power system, shown in figure 1 , to be packagable in the shuttle and a viable system, needs a radiator whose value of emittance is at least 0.85 at operating temperatures of 700 to $900 \mathrm{~K}$ (ref. 1). Materials currently considered for use as a radiator do not have such a high value of emittance. It is, however, possible to obtain a high thermal emittance through the use of either a coating (ref. 2), or a change in surface morphology (ref. 3). Coatings tend to have intrinsic stress (ref. 4) and can spall when thermally cycled or raised to elevated temperature levels (ref. 5). These phenomena, however do not occur on surfaces that have been ion beam textured. Ion beam texturing induces a physical change in the surface of a material and thus changes its optical properties (refs, 3 and 6 ). Thus, a high emittance can be obtained by a morphology change on the surface, one that does not alter the surface chemistry and hence maintains its integrity. The first extensive study of the ion beam texturing process was performed by Wehner 
and Hajicek (ref. 7). Hudson (ref. 8) studied the texturing of over thirty elements using an ion source. Kaufman and Robinson (ref. 9) showed that to obtain uniform changes in surface morphology over a large area, using ion source texturing techniques, substrate temperature was important. other parameters of importance were high current density, energy, and seed material during texturing. Variations of these parameters could lead to a desirable value of emittance for a given material. The system chosen to ion texture materials was the discharge chamber of a $30 \mathrm{~cm}$ ion source, essentially a simple triode configuration. This system was used by Curren (ref. 10) to obtain uniformly textured copper specimen $4 \mathrm{in}$. in diameter, and can be scaled to meet the production requirements necessary for texturing large radiator areas.

In this study four materials, stainless steel (S.S.) type 304, titanium 16 percent vanadium, 2.5 percent aluminum $(T i(16,2.5))$, copper $(\mathrm{Cu})$, and niobium 1 percent zirconium $(\mathrm{Nb}(1) \mathrm{Zr}$ ) of general interest for radiator applications have been textured. Scanning electron photomicrographs have been taken of each surface to characterize the resulting morphology. Measurements of the spectral total reflectance (specular and diffuse) between 1.5 and $15 \mu \mathrm{m}$ were made using a Hohlraum reflectometer. Total emittance normalized to 700 and $900 \mathrm{~K}$ blackbodies were calculated from these data. Textured samples were also exposed in an RF plasma asher to evaluate their durability to simulated atomic oxygen (ref. 11).

\section{APPARATUS AND PROCEDURE}

\section{Discharge Chamber Texturing}

A schematic illustrating the various parts of the ion source used in ion texturing is shown in figure 2 . Sample materials to be textured were placed in the holder as shown in figure 2 and then subjected to an ion beam made up of argon ions in a background vacuum environment of $2.0 \times 10^{-5}$ torr. Argon gas was fed into the discharge chamber at a flow rate of approximately $80 \mathrm{scc} / \mathrm{min}$, ionized, and then accelerated by the negative $1500 \mathrm{~V}$ potential maintained on the sample. The sample holder was equipped with a tantalum heater which allowed for varying sample temperature while holding all other parameters constant. During testing of various candidate radiator materials the sample temperature, surface current density, and exposure time were varied in order to achieve the highest possible emitlance. Figure 3 shows a sample resting in its holder prior to being installed in the discharge chamber. The samples measured $2.35 \mathrm{~cm}$ in diameter and had thicknesses varying from $0.078 \mathrm{~cm}$ for S.S. to $0.183 \mathrm{~cm}$ for Ti. Before being placed in the holder, all samples were cleaned with very fine grained sandpaper, and then rinsed with acetone and high-purity ethyl alcohol on absorbent paper to remove contaminants. The sample was surrounded by a tantalum skirt which was secured $0.79 \mathrm{~cm}$ above the holder, and sloped outward at a $45^{\circ}$ angle. The Ta skirt was used as a seed material (ref. 3) to initiate and sustain the texturing process. Some amount of experimenting was necessary to determine the proper height required for obtaining a uniform texture on the material surface. Thermocouples were also attached to the holder and to the sample to monitor temperature levels. A molybdenum ring fits over the sample to ensure that good electrical contact was made between the sample and the holder. While ion beam-texturing, the tantalum skirt was at the same electrical potential as the sample $(-1500 \mathrm{~V})$. However, for the last $10 \mathrm{sec}$ of texturing, the potential was removed thus allowing for removal of the unwanted tantalum from the textured sample. 
All four materials were ion textured by $1500 \mathrm{eV}$ argon ions. Each material was exposed in the discharge chamber for different lengths of time. The ultimate change in surface morphology was obtained for a given exposure condition by texturing the samples until there were no further changes in morphology. The resulting microstructures were unique for each material and reproducible under identical conditions. Exposure times to reach morphology equilibrium are given in table $I$.

High values of emittance are desired at 700 and $900 \mathrm{~K}$, thus low values of reflectance are needed in the wavelength region corresponding to 4 and $3 \mu \mathrm{m}$ respectively. It has been shown that the average separation between cones is controlled by substrate temperatures during the texturing (ref. 9). It was with this in mind that the specimens were taken to elevated temperatures approaching $1000 \mathrm{~K}$ during texturing.

\section{Ref lectance Measurements}

Optical properties of the materials in the infrared region ( 2 to $15 \mu \mathrm{m}$ ) were obtained using a hohlraum reflectometer, shown in figure 4 . The hohlraum reflectometer measures total normal or diffuse reflectance. The ion textured samples $2.38 \mathrm{~cm}$ in diameter, in a water cooled holder were placed into a chamber that had a nickel oxide coating which was heated to $873 \mathrm{~K}$. The reflected radiation from the sample was directed into a monochromator. The monochromator was driven by an electric motor to obtain a continuous reflectance curve for the wavelength region of 2 to $15 \mu \mathrm{m}$. The nickel oxide coating on the wall of the chamber ( $\sim 0.98$ blackbody) was used as a reference and continuous reflectance curves were obtained for both the sample and the nickel oxide wall. The spectral reflectance then is the ratio of the ion textured sample reflectance at one wavelength. From this reflectance data values of total emittance were obtained by normalizing to 700 and $900 \mathrm{~K}$ blackbodies.

The calculation for total emittance is:

$$
\varepsilon_{T}=1-\frac{\int \rho(\lambda) \varphi(\lambda) \mathrm{d} \lambda}{\int \varphi(\lambda) \mathrm{d} \lambda} \approx 1-\frac{\sum_{i=1}^{27} \rho i(\lambda) \varphi i(\lambda)(\Delta \lambda i)}{\sum_{i=1}^{27} \varphi i(\lambda)(\Delta \lambda i)}
$$

where $\rho i(\lambda)$ is the spectral reflectance at $i=1,2.5,3, \ldots, 15 \mu \mathrm{m}$. $\varphi i(\lambda)$ is the spectral irradiance from a 700 or $900 \mathrm{~K}$ blackbody. ( $\Delta \lambda i)$ is $0.5 \mu \mathrm{m}$.

Asher

Plasma ashers employing a $13.45 \mathrm{MHz}$ air discharge to test a material's ability to survive long term exposure to atomic oxygen in simulated low earth orbit (LEO). The relative rates of degradation between time in an asher and exposure in LEO varies with different materials. However, materials that survive in LEO generally survive in ashers and those that degrade in I.EO degrade in ashers (ref. 11). The textured materials were exposed for $114 \mathrm{hr}$ 
each in a plasma asher to evaluate the durability of their optical properties to atomic oxygen.

\section{RESULTS AND DISCUSSION}

Figure 5 shows the development of the morphology of a copper specimen exposed for $0.5,1$, and $2 \mathrm{hr}$ to $1500 \mathrm{eV}$ argon ions using tantalum as a seed material with the $C u$ specimen at $943 \mathrm{~K}$. The fully developed structure occurs in $2 \mathrm{hr}$. The fully developed surface morphology of textured S.S. and Ti are shown in figure 6 . The resulting structures are of the form of cones, pyramids, ridges, or wavelike formations. The steep walls of these structures can be highly absorbing due to multiple reflections of incident photons on the walls. Since some of the textures have dimensions of the order of radiation in the micron region, these surfaces have low reflectivity or high emittance in the infrared.

$\mathrm{Nb}(1) \mathrm{Zr}$ was also textured during these experimental conditions but developed the morphology shown in figure 7. The dimensions of this morphology are large compared to the wavelengths region of interest and hence did not yield high values of emittance (see table I). Shown in figure 8 is the spectral total emittance between 1.5 and $15.0 \mu \mathrm{m}$ for $\mathrm{Ti}(16,2.5)$, textured at $1120 \mathrm{~K}$ for times varying from $15 \mathrm{~min}$ to $2 \mathrm{hr}$. After $15 \mathrm{~min}$ not enough structures were formed to make much of a difference in the spectral emittance at any wavelength. The values of spectral emitlance obtained after $2 \mathrm{hr}$ of texturing were for a fully developed surface morphology. Continued texturing of Ti at these conditions produced no further changes in the values of emittance. Total emittance values for $\mathrm{Ti}(16,2.5)$ at 700 and $900 \mathrm{~K}$ were 0.75 and 0.80 , respectively. It should be noted that diffuse reflectance measurements made on the samples with fully developed morphologies showed that the measured reflectances were totally diffuse. Hence, the value of emittance presented herein are total emittance values.

Figure 9 shows the spectral emittance of the cu sample. The values of emittance for Cu were the highest obtained in this study, a very high 0.978 at $700 \mathrm{~K}$ and 0.983 at $900 \mathrm{~K}$. Shown in figure 10 are the spectral emittance for three S.S. type 304 samples; one S.S. sample's emitlance was enhanced by dis charge chamber texturing only, a second S.S. sample was immersed in $\mathrm{HCl}$ acid for a few minutes and then discharge chamber textured, the third was treated with $\mathrm{HCl}$, discharge chamber textured, and then ashed for $2 \mathrm{hr}$. There are noted differences in the spectral emittance, especially at wavelengths greater than $10 \mu \mathrm{m}$. The values of total emittance at 700 and $900 \mathrm{~K}$ did not vary much (table I) by the difference in treatment for the first two samples, but did decrease after exposure to the asher. Using S.S. as a radiator material in low earth orbit without protection from atomic oxygen could be a problem. However, both $\mathrm{Cu}$ and $\mathrm{Ti}$ did not change in emittance after exposure to the asher. The results of these studies are preliminary, and the conditions in the discharge chamber, including temperature and seed material have not been fully explored or optimized. However, it is clear that the discharge chamber conditions used in this study did produce values of emittance for $\mathrm{Cu}$ and S.S. that exceeded the goals of 0.85 at 700 and $900 \mathrm{~K}$. It is felt that under the proper conditions $\mathrm{Nb}(1) \mathrm{Zr}$ or $\mathrm{Ti}$ could be discharge chamber textured to produce higher values of emittance than those obtained herein. It should also be pointed out that there are other methods being used to improve upon the emittance of space radiator materials. These methods include immersion in acids, kiln air 
treating, sand blasting, electro-chemical treatment, and combinations of each. Some of these methods do produce emittance values greater than 0.85 for some materials (ref. 12).

\section{CONCLUDING REMARKS}

Discharge chamber texturing can be used to develop morphologies in copper, titanium, stainless steel, and $\mathrm{Nb}(1) 2 \mathrm{r}$. Each material developed a unique morphology for the discharge chamber conditions explored in this paper and were reproducible. These microstructures resulted in extremely high values of thermal emittance (0.978 and 0.983 ) for copper at 700 and $900 \mathrm{~K}$, respectively and 0.87 for stainless steel type 304 , exceeding the 0.85 needed for SP 100 radiators. Ti and $\mathrm{Nb}(1) \mathrm{Zr}$ although texturable, did not, under the present experimental conditions yield required emittances. The results of ashing indicate no change in emittance for copper, but a decrease in emittance below 0.85 for stainless steel, indicating a need to protect textured S.S. from the atomic oxygen environment. Thus, a discharge chamber of an ion source can be used to change a materials surface morphology to obtain values of thermal emittance higher than those of the pristine materials.

\section{REFERENCES}

1. H.W. Brandhorst, Jr., A.J. Juhasz, B.I. Jones, "Alternative Power Generation Concepts for Space," NASA TM-88876, 1986.

2. J. Jurisson, R.E. Petersen, and H.Y.B. Mar., J. Vac. Sci. Techno1. 12, $1010(19 \% 5)$.

3. W.R. Hudson, A.J. Weigand, and M.J. Mirtick, "Optical Properties of Ion Beam Textured Metals," NASA TM X-73598, 1977.

4. S.M. Kane and K.Y. Ahn, J. Vac. Sci. Technol. 16, 171 (1979).

5. M.J. Mirtich, C.Y. Nieh, J.F. Wallace, Thin Solid Films 84, 295 (1082).

6. S.M. Rossnagel and R.S. Robinson, J. Vac. Sci. Technol. 20, 336 (1982).

7. R.S. Berg and G.J. Kominiak, J. Vac. Sci. Technol. 13, 403 (1976).

8. W.R. Hudson, J. Vac. Sci. Technol. 14, 286 (1977).

9. H.R. Kaufman and R.S. Robinson, J. Vac. Sci. Technol. 16, 175 (1979).

10. A.N. Curren and K.A. Jensen, "Textured Carbon on Copper," NASA TP-2543, 1985.

11. B.A. Banks, M.J. Mirtich, S.K. Rutledge, D.M. Swec, and H.K. Nahra, "Ion Beam Sputter-Deposited Thin Film Coatings for Protection of Spacecraft Polymers in Low Earth Orbit," NASA 1M-87051, 1985.

12. S.K. Rutledge, B.A. Banks, M.J. Mirtich, R. Lebed, D. Hotes, M. Kussmau1, Paper L3.7, presented at the spring meeting of the Materials Research Society, Anaheim, CA, Apr. $198 \%$. 
ORIGINAT PAGE IS OF POOR OIJALITY

OF POOR OIALITY
TABLE I.

\begin{tabular}{|c|c|c|c|c|c|}
\hline \multirow[t]{3}{*}{ Material } & \multirow{3}{*}{$\begin{array}{c}\text { Exposure time } \\
\text { to morphology } \\
\text { equilibrium, } \\
\text { hr }\end{array}$} & \multicolumn{2}{|c|}{ Emittance } & \multirow{2}{*}{\multicolumn{2}{|c|}{$\begin{array}{c}\text { Emittance after } \\
\text { ashing }\end{array}$}} \\
\hline & & \multirow{2}{*}{$700 \mathrm{~K}$} & \multirow{2}{*}{$900 \mathrm{~K}$} & & \\
\hline & & & & $700 \mathrm{~K}$ & $900 \mathrm{~K}$ \\
\hline $\mathrm{Cu}$ & 2 & 0.978 & 0.983 & 0.978 & 0.983 \\
\hline Ti & & .75 & ${ }^{a} .80$ & & \\
\hline$(16,2.5)$ & 2 & .478 & .521 & .478 & .521 \\
\hline $\mathrm{Nb}(1) \mathrm{Zr}$ & 3 & .352 & .376 & .352 & .376 \\
\hline S.S. type 304 & 2 & .87 & .89 & .79 & .81 \\
\hline $\begin{array}{l}\text { S.S. type } 304 \\
\text { and HCL }\end{array}$ & 2 & .89 & .89 & - & - \\
\hline
\end{tabular}

$a_{\text {Best value obtained for }} \mathrm{Ti}(16,2.5)$.

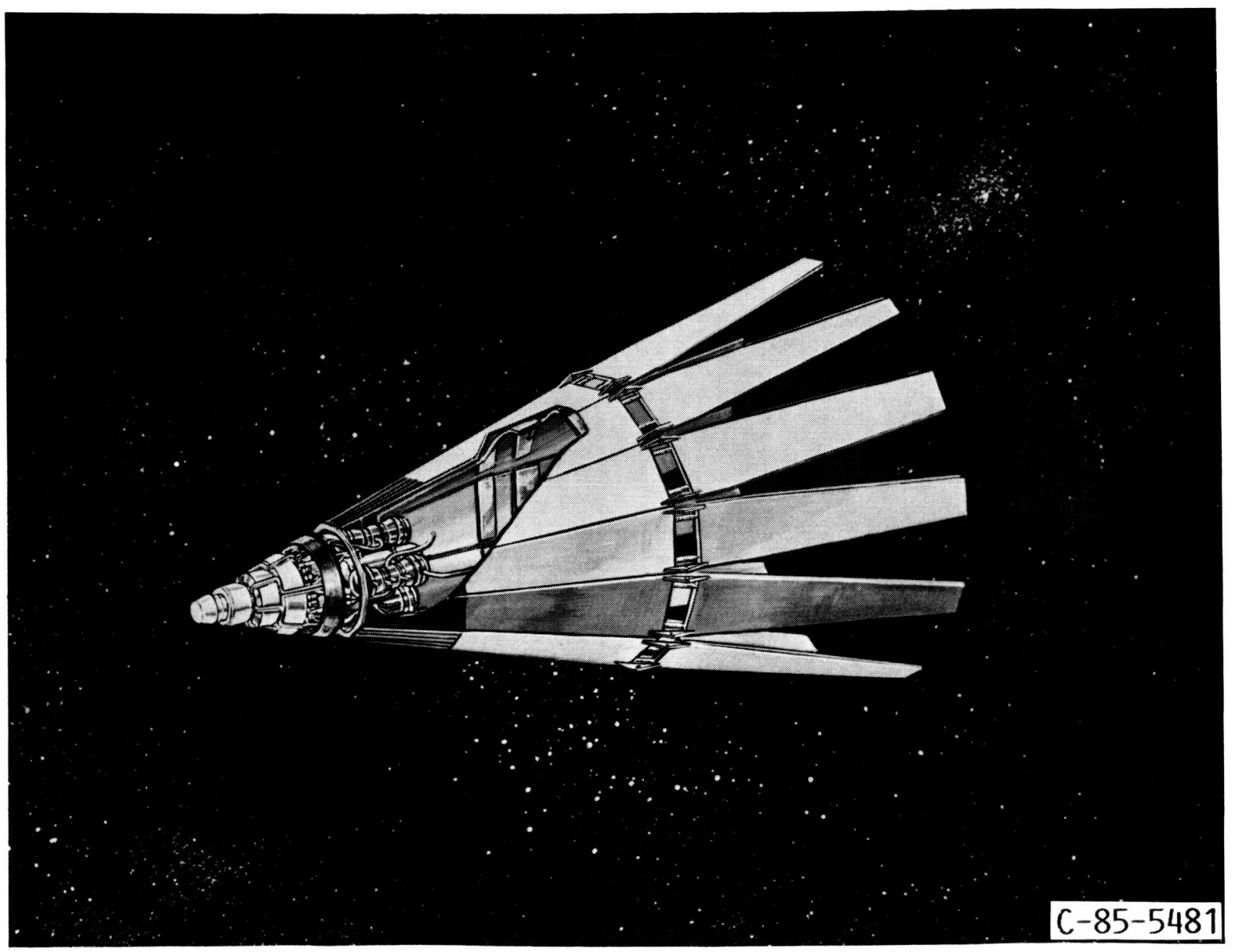

FIGURE 1. - SP 100 POWER SYSTEM CONCEPT. 


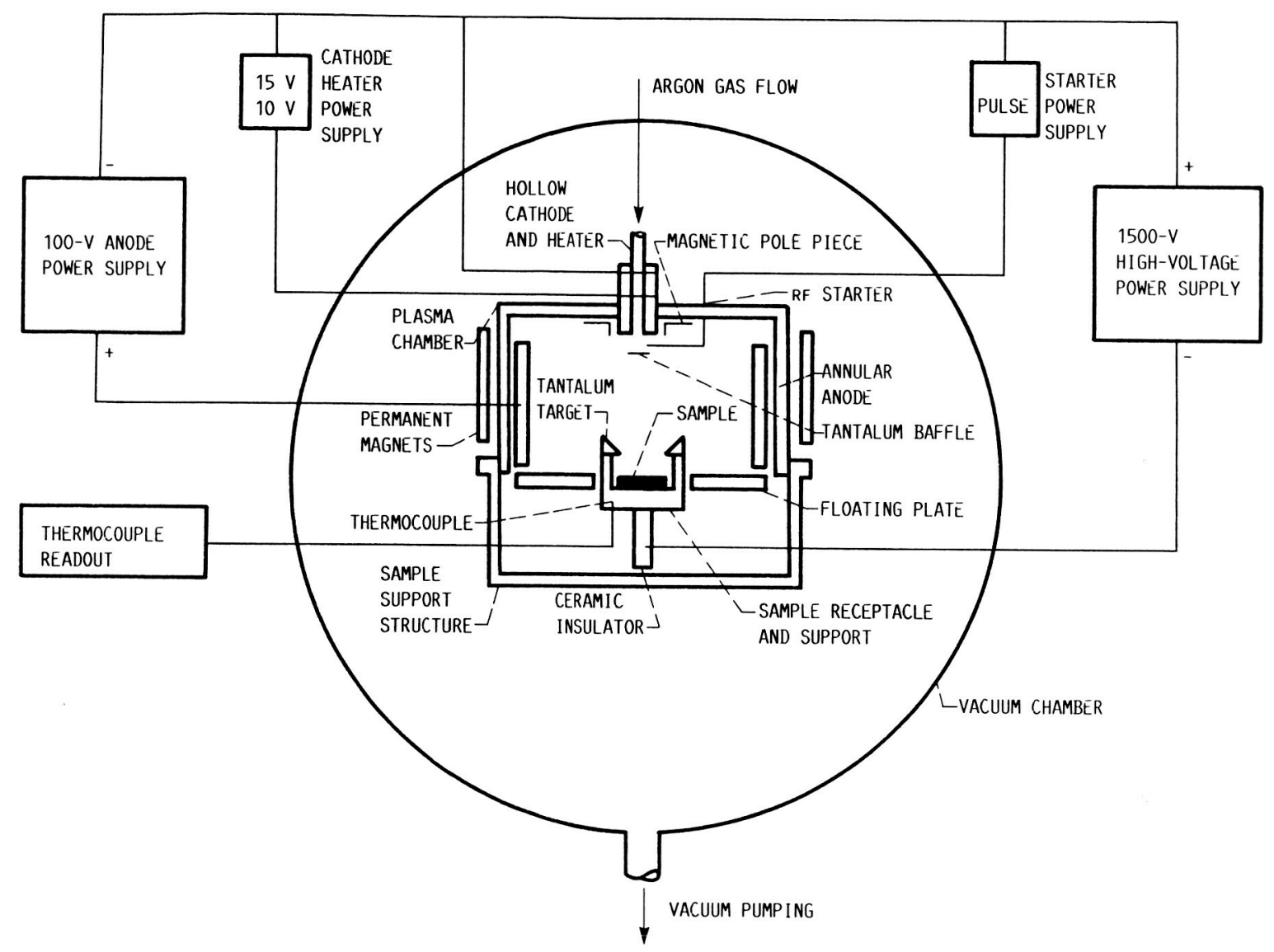

Figure 2. - SChematic of apparatus used for discharge chamber teXturing. 


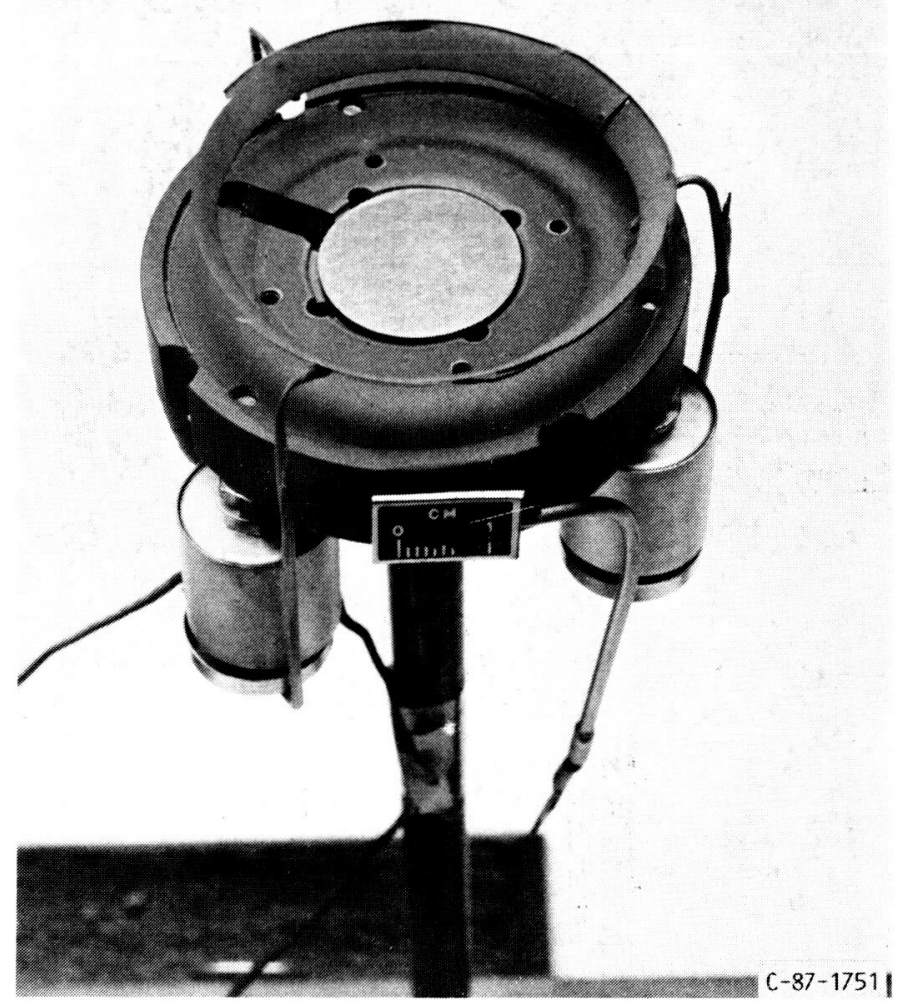

FIgURE 3. - PHOTO OF SAMPLE IN ITS HOLDER.

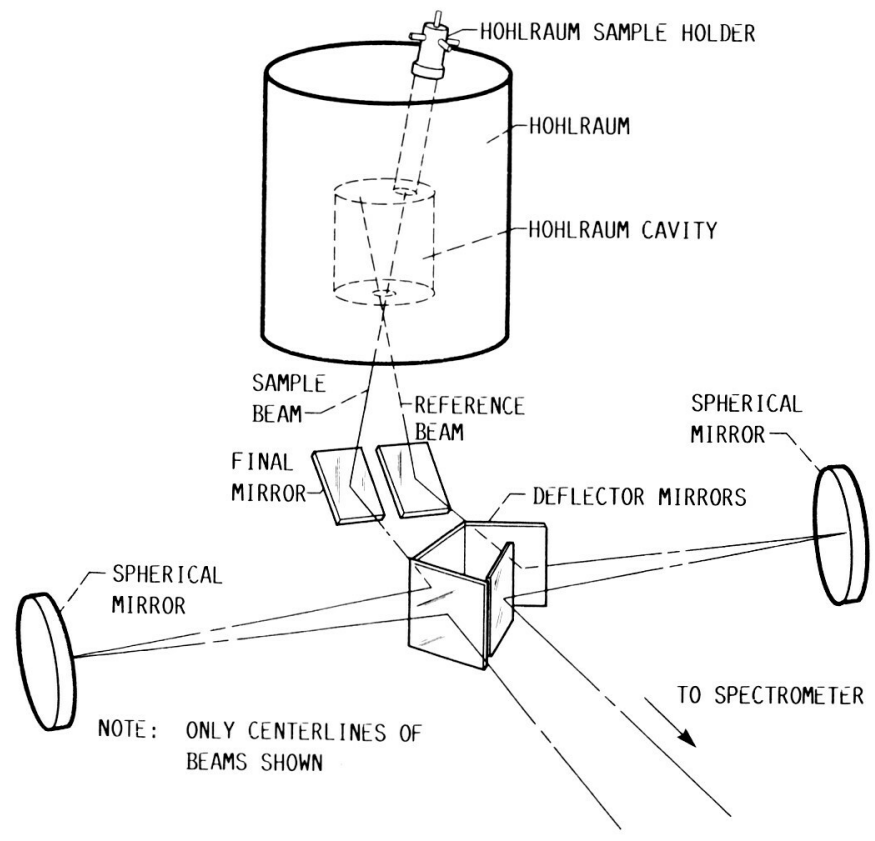

FIGURE 4. - OPTICAL PATH OF HOHLRAUM REFLECTOMETER. 


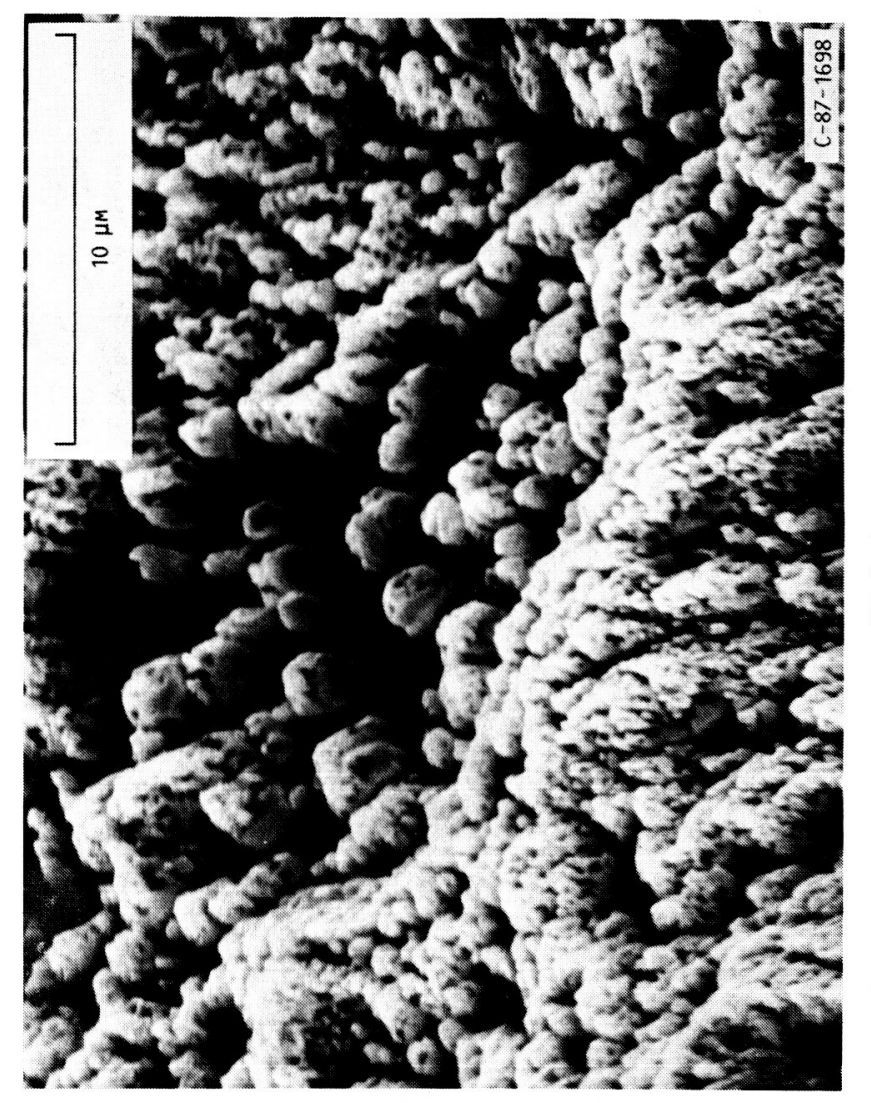

ORIGINAL PAGE IS
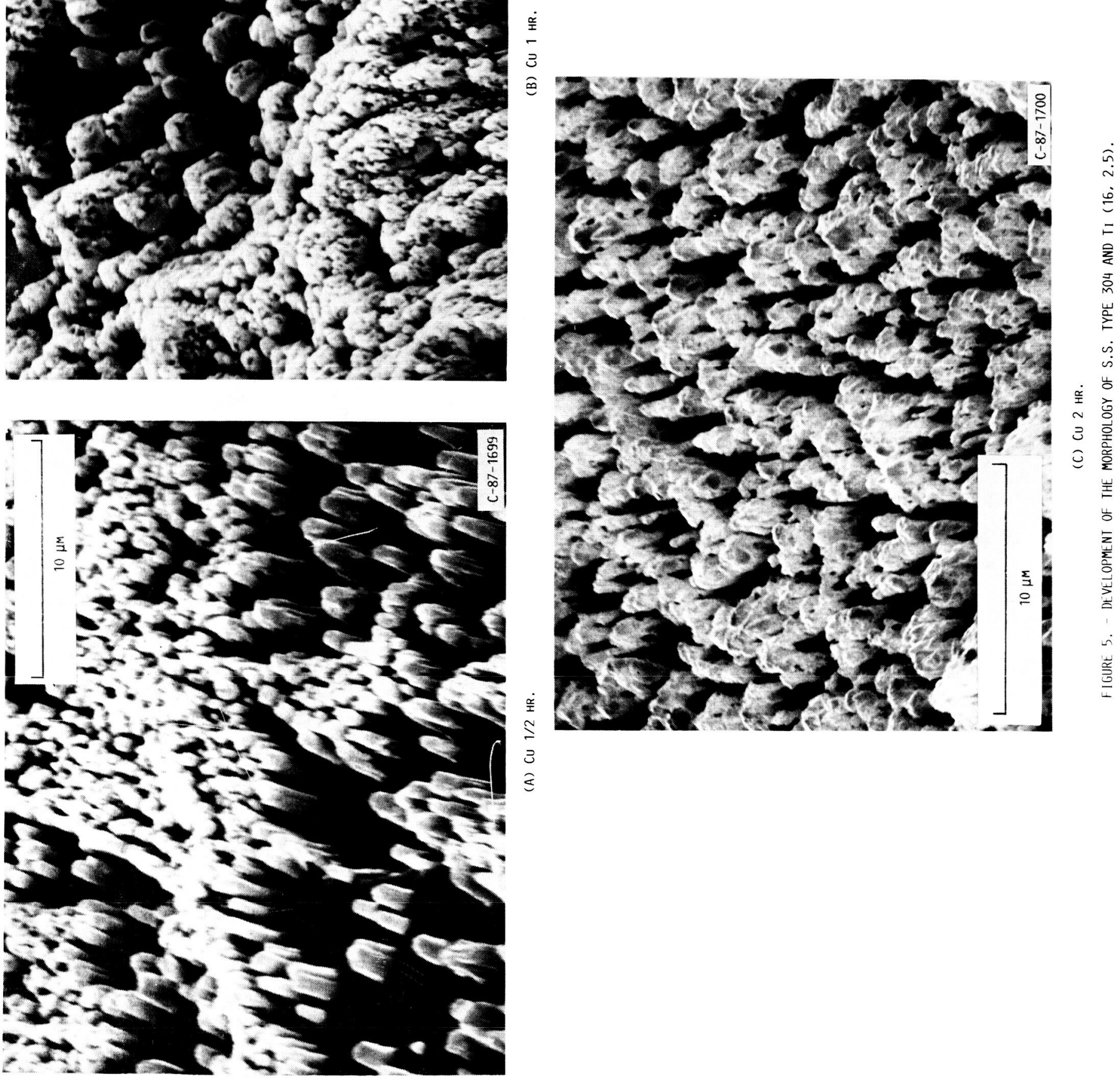
ORIGINAC PAGE IS

OF POOR QUALITY

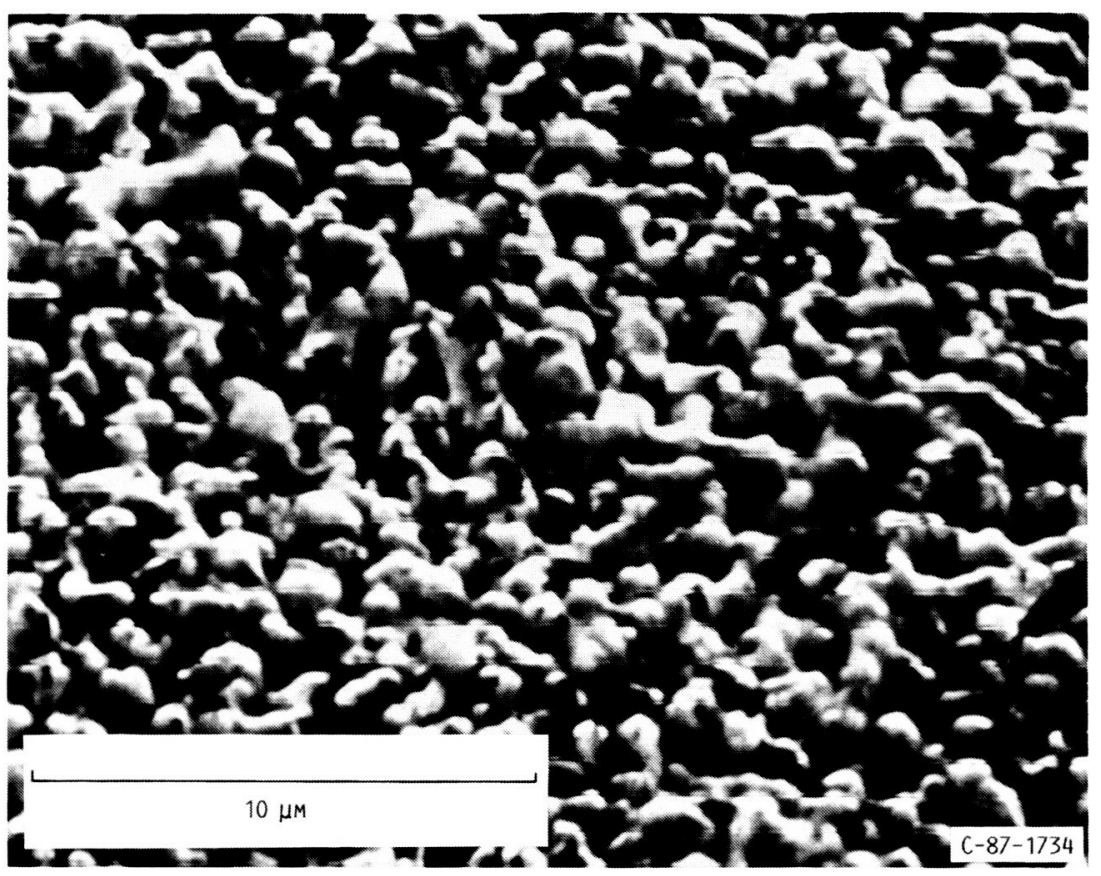

(A) S.S TYPE 304.

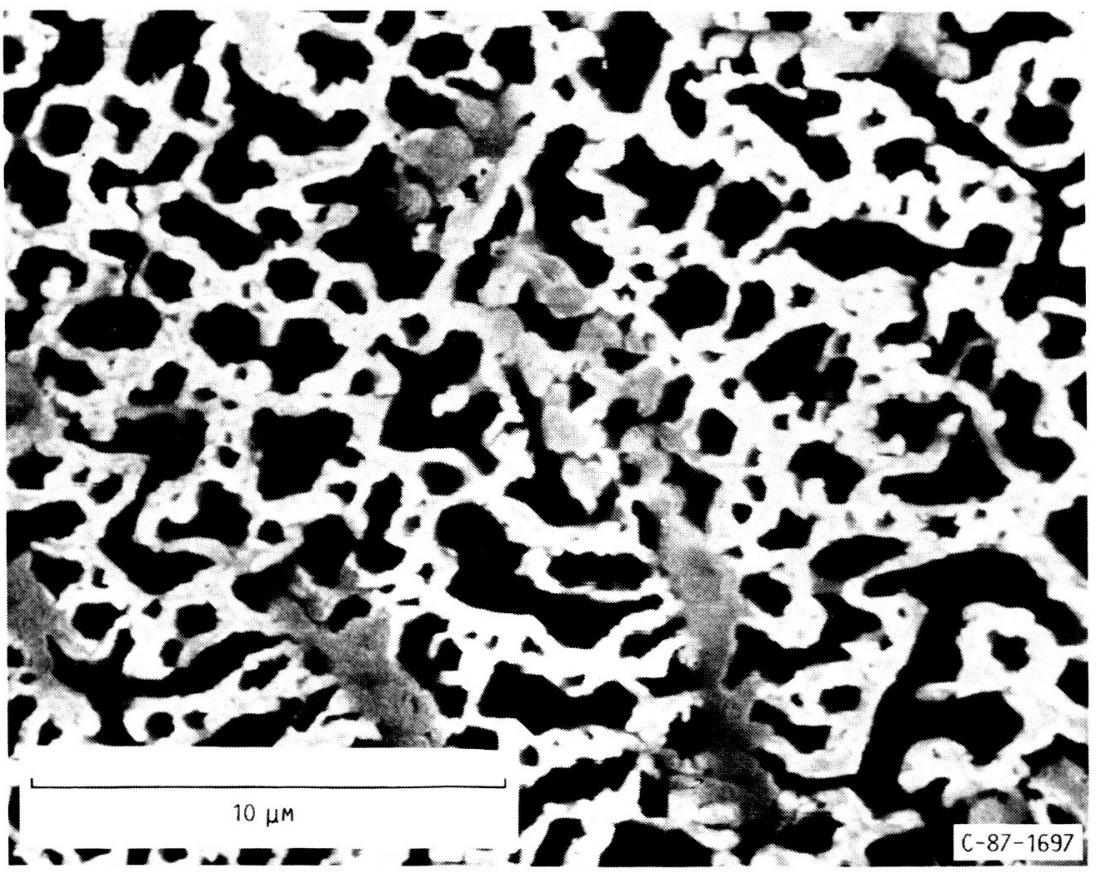

(B) TI $(16 \mathrm{~V}, 2.5 \mathrm{Al})$.

FIGURE 6. - FULLY DEVELOPED MORPHOLOGY OF S.S. TYPE 304 AND TI $(16,2.5)$. 

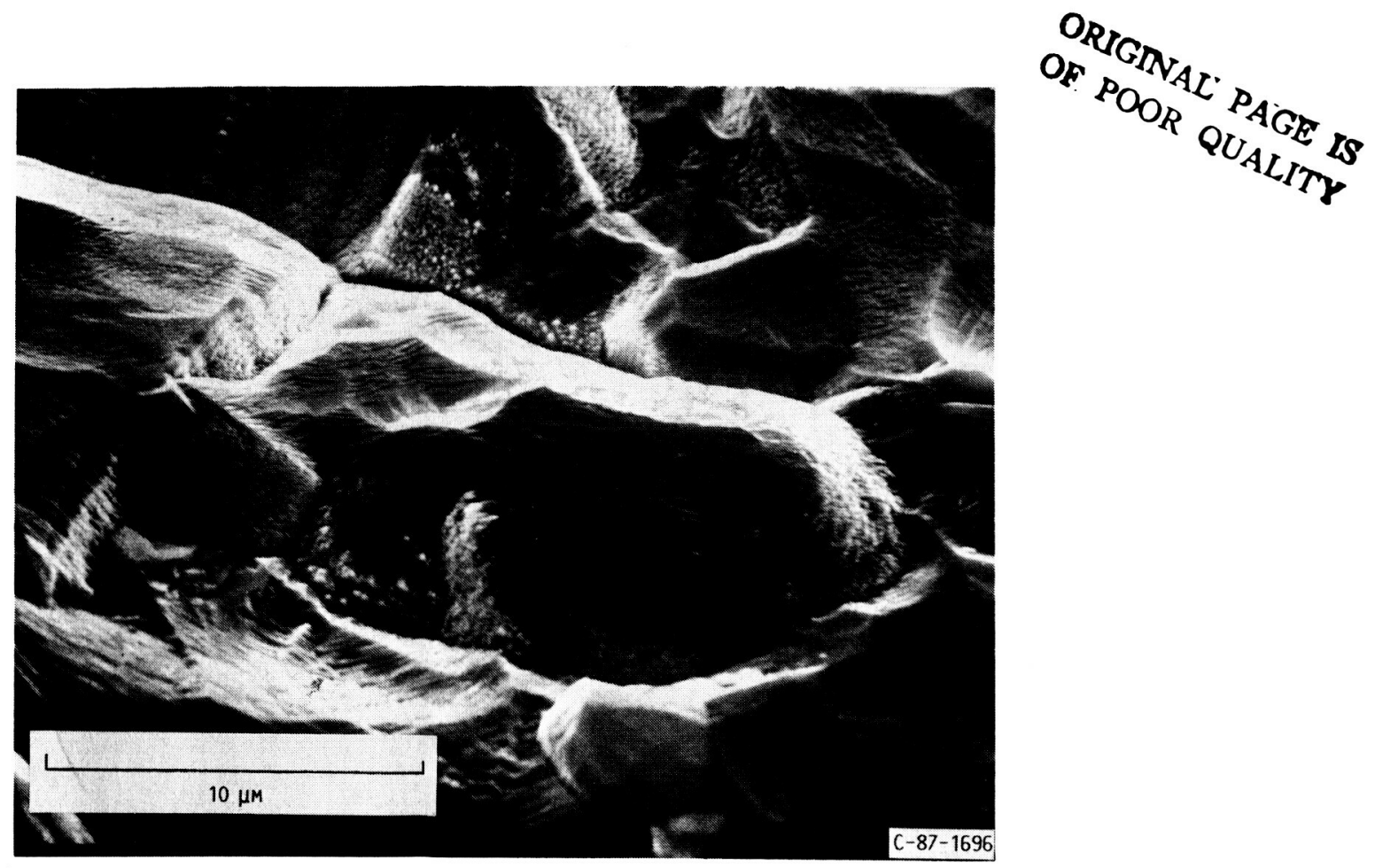

FIGURE 7. - MORPHOLOGY OF NB (1\%) ZR.

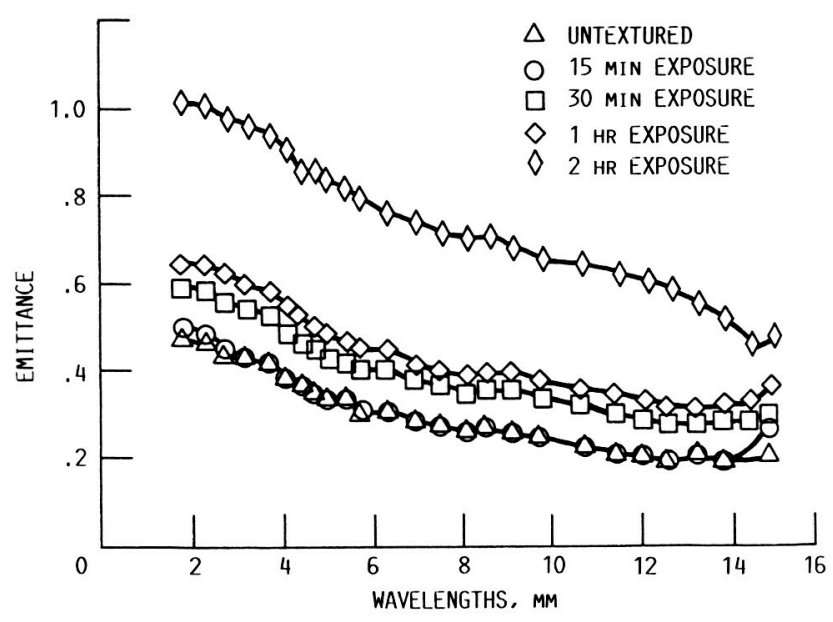

FIGURE 8. - SPECTRAL EMITTANCE OF TI $(16,2.5)$ AFTER DISCHARGE CHAMBER TEXTURING FOR VARIOUS LENGTHS OF TIME.

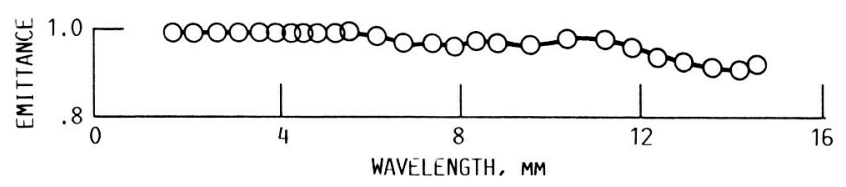

FIGURE 9. - SPECTRAL EMITTANCE OF COPPER WITH FULLY DEVELOPED MORPHOLOGY.

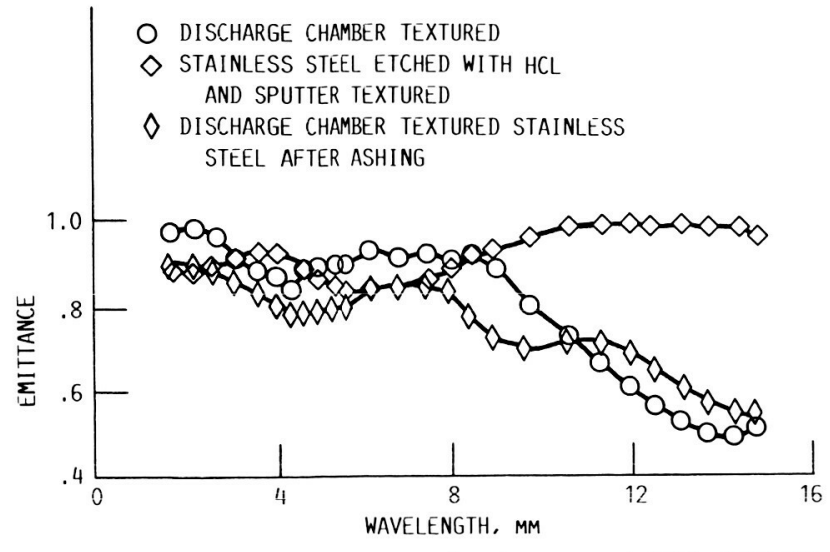

FIGURE 10. - SPECTRAL EMITTANCE OF STAINLESS STEEL TYPE 304 AFTER VARIOUS TREATMENTS. 


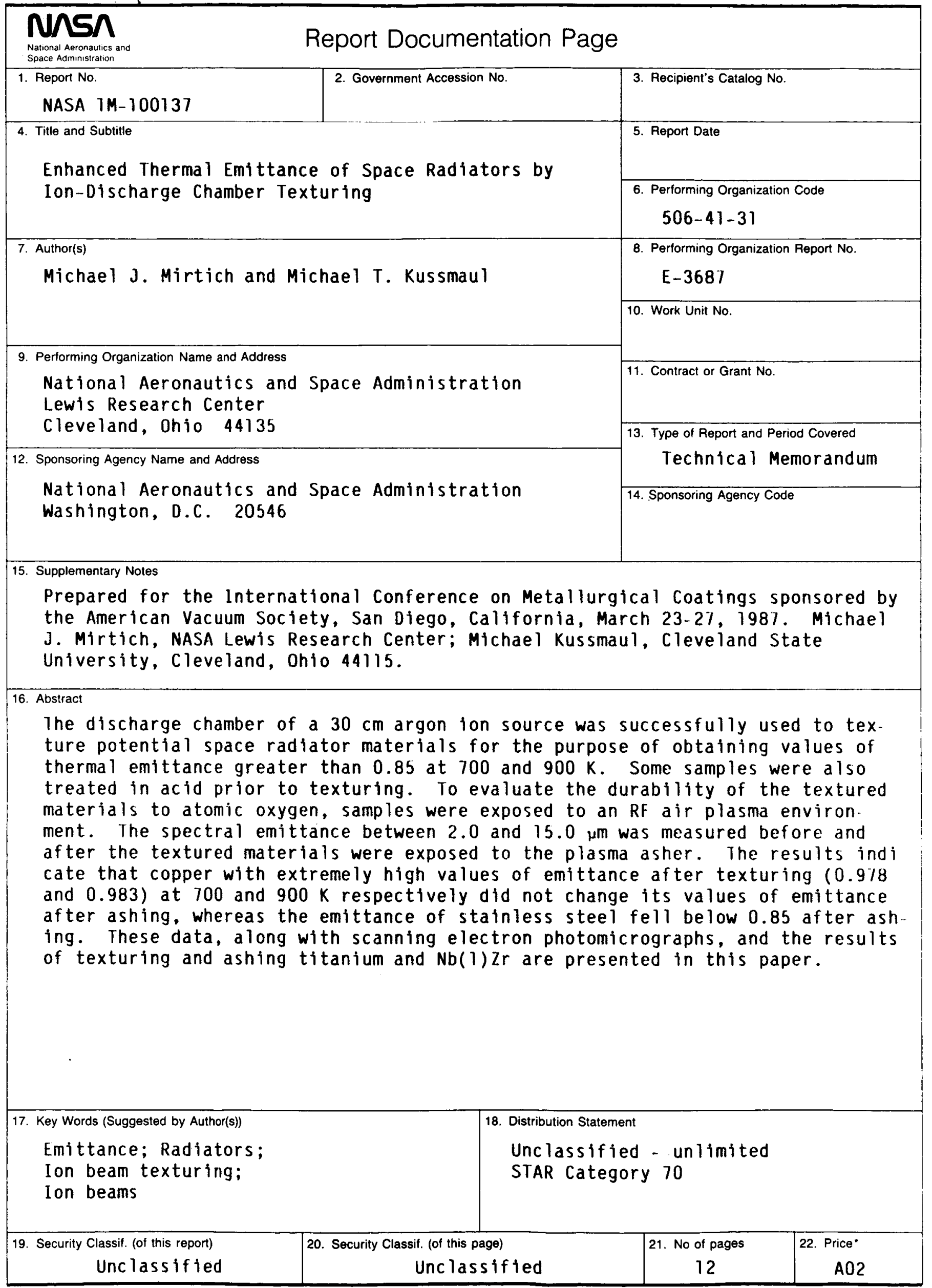

NASA FORM 1626 OCT $86 \quad$ *For sale by the National Technical Information Service, Springfield, Virginia 22161 